\title{
Invited review: Authentication of milk by direct and indirect analysis of triacylglycerol molecular species
}

\author{
L. Cossignani, L. Pollini, and F. Blasi* \\ Department of Pharmaceutical Sciences, Section of Food Science and Nutrition, University of Perugia, Via San Costanzo, 06126 Perugia, Italy
}

\section{ABSTRACT}

Milk, milk-based products, and milk derivatives represent an important group of food commodities, with high nutritional value and widely consumed by large segment of consumers, including pregnant women, newborns, children, and the elderly. Food authentication is a rapidly growing field because of increasing consumer awareness regarding food quality and safety. This review attempts to critically summarize the status of direct and indirect analysis of the molecular species of triacylglycerols (TAG) used to assess the authenticity of milk. Identification and quantification of TAG molecular species in milk fat can be accurately performed even though analytical approaches focused on fraud evaluation should be developed. Recent analytical breakthroughs and novel techniques are discussed, along with their applications in milk authentication.

Key words: authentication, milk quality, triacylglycerol, lipid analysis

\section{INTRODUCTION}

The perceived quality of a food is a very important factor for the consumer, who often associates it with the concept of authenticity, meaning the adherence of the product to what is written on the label. The authenticity of dairy products is linked to animal species, geographic origin, and processing or production technology (Hrbek et al., 2014), although inter- and intra-species variability factors, such feeding practices, breed or lactation conditions, should also be considered (Jensen, 2002). The authenticity of dairy products often has a strong effect on the final economic value of the food (Di Stefano et al., 2012).

Recently, an initiative of the European Parliament identified several foods, including dairy products, that are common targets of fraudulent activities. The

Received January 17, 2019.

Accepted March 11, 2019.

*Corresponding author: francesca.blasi@unipg.it
European Union Joint Research Centre's (EU-JRC) actions in the area of food authenticity help counteract food fraud by applying the best available science to develop standard methodologies and best practices guides, supported by advanced analytical methods. The JRC publishes a summary of articles every month on food fraud and adulteration (EU-JRC, 2018).

Regarding the authentication of milk, a few older reviews report methods for the analysis of triacylglycerols (TAG) aimed at verifying milk quality and detecting adulteration (Lipp, 1995). Moreover, there is a great deal of interest in analysis of TAG species contained in milk fat because of their influence on physiological, nutritional, and technological aspects (Fontecha et al., 2005). Together with fish oils, milk lipids are the most complex dietary fats. Analysis of TAG in milk and dairy products is a very difficult task because of their extraordinary variety of fatty acids (Blasi et al., 2008; Cossignani et al., 2014). It has been reported that milk fat contains approximately 400 different fatty acids (FA), which is reflected by a wide variety of possible TAG molecular species; the possible number of TAG molecular species could exceed 1,300 (Lipp, 1995; Månsson, 2008). It is therefore important to analyze TAG profiles, including regioisomers and enantiomers, not only to understand the physical, chemical, and nutritional properties of milk fats, but also to verify milk authenticity ( ̌̌ezanka et al., 2017). In this regard, identifying the species origin is also important to consumers because of the economic loss arising from fraudulent substitution, as well as aspects related to food safety (Cubero-Leon et al., 2014) and religion (Abbas et al., 2018).

The use of rapid, effective, and reliable analytical methods for TAG molecular species represents a valuable and irreplaceable tool to verify the authenticity and traceability of milk products. The analytical techniques that can be used for this purpose are chromatographic (liquid or gas chromatography) or nonchromatographic techniques, such as vibrational spectroscopy (nearinfrared and mid infrared spectroscopy), hyper-spectral imaging, nuclear magnetic resonance spectroscopy and Raman spectroscopy. Other techniques include opti- 
cal and infrared microscopy, electronic spin resonance spectroscopy, PCR, MALDI-TOF MS (Picariello et al., 2007; Calvano et al., 2013; Tzompa-Sosa et al., 2018), and enzymatic assays.

This review focuses on chromatographic procedures for the analysis of the TAG fraction in order to verify the authenticity of milk, in particular identifying the species origin. The objective was to highlight the advantages and disadvantages of several methods developed to assess authenticity using TAG molecular species.

\section{EXTRACTION METHODS OF MILK LIPIDS}

Extraction is a critical step in the analysis of lipids, because contamination or improper extraction of components could lead to misinterpretation. Before being carefully analyzed, samples should be freshly prepared, homogenized, and then extracted. It is important to prevent lipid degradation and to prevent or minimize the presence of artifacts, which can compromise the identification and quantification of the lipid fraction components. The addition of synthetic antioxidants might be recommended before extraction to avoid lipid oxidation. Alternatively, a commercially available oxygen absorber could be placed inside the sample package, or nitrogen flow could be applied before closing vials (Christie and Han, 2012).

The most commonly used lipid extraction techniques in lipidomics are liquid-liquid extraction (LLE) and solid-phase extraction (SPE). Other techniques such as solid-phase microextraction (SPME), ultrasonicassisted extraction, and dispersive liquid-liquid microextraction are used sporadically.

For extraction of total milk lipids, the most widely used methods are classical LLE procedures based on a chloroform-methanol-water solvent system and 2-phase partition of lipids (Folch et al., 1957; Bligh and Dyer, 1959). Both methods are gold standards for the extraction of a broad range of lipid classes from samples of different types, milk and dairy products included (Cequier-Sánchez et al., 2008). Some authors have reported the need to replace the chloroform-methanol mixture with less toxic solvents, such as hexane-isopropanol, to avoid the major health, security, and regulatory problems associated with the use of chloroform (CequierSánchez et al., 2008).

These classic extraction methods have been applied for decades to different milk lipid classes but the extraction efficiency may be lower for small TAG (Christie and Han, 2012), glycerophospholipids, and cerebrosides (Liu et al., 2018). This could affect qualitative and quantitative analysis of lipids and hinder the understanding of their biosynthesis, biological functions, and product authentication.
Liu et al. (2016) developed a single-phase extraction method, efficient for extracting both polar and nonpolar lipids from milk. A butanol:methanol:chloroform (3:5:4) mixture is directly added to the milk, and no solvent removal and reconstitution steps are necessary. The method is very simple but comprehensive and thus suitable for high-throughput liquid chromatography (LC)-MS lipidomic analysis; the extraction efficiency for TAG was similar to that of the Folch method, even if the method proposed by Liu and collaborators was better for more polar lipids such as phospholipids.

Reference methods for milk lipid extraction are based on mixtures of ethers (AOAC International, 2016; ISO, 2010a). Franz von Soxhlet first described a semicontinuous method based on automatic solvent extraction using diethyl ether for milk lipids. The application of high pressure, ultrasound, or microwaves has decreased or minimized the negative aspects (time-consuming, requiring a large amount of solvent and an evaporation-concentration step after extraction) of classical conventional Soxhlet extraction (Luque de Castro and Priego-Capote, 2010).

Recently, methyl-tert-butyl ether-based methods have gained popularity (Villaseñor et al., 2014). The advantage of this simple method is that the organic phase containing lipids constitutes the upper layer, minimizing the potential of cross contamination and enabling a faster and cleaner lipid recovery.

The effect of different lipid extraction methods on lipid research has been evaluated, and numerous comparative studies have been reported, on both animal (Pérez-Palacios et al., 2008; Sardenne et al., 2019) and vegetable (Li et al., 2014; Blasi et al., 2017) foods.

Classical LLE methods are particularly time consuming and require large amounts of organic solvents. To extract emulsified fat globules suspended in the aqueous phase of the milk efficiently, the globules have to be broken carefully. This condition is met by using accelerated solvent extraction, a pressurized liquid extraction method based on elevated pressure and temperature (Luque de Castro and Priego-Capote, 2010; CastroGómez et al., 2014).

Garwolińska et al. (2017) developed a new, rapid, and simple method based on SPME with a fiber coated with a silica-based sorbent modified with $\mathrm{C} 18$ groups to extract a broad range of lipids, such as glycerophosphatidylcholine, sphingomyelins, diacylglycerols (DAG), and TAG, directly from milk samples.

Despite the low sample throughput, long time, and large solvent consumption, the most widely used techniques for fat extraction are based on the method developed by Folch or its modification in official method 989.05 (AOAC International, 2016) or according to 1211:2010/IDF 1:2010 (ISO, 2010a). The main prob- 
Table 1. Methods published after 2000 for the determination of triacylglycerols (TAG) in milk fat using high-resolution GC methods

\begin{tabular}{|c|c|c|c|c|}
\hline Milk & Detector $^{1}$ & Stationary phase ${ }^{2}$ & $\begin{array}{l}\text { TAG } \\
\text { molecular } \\
\text { species }\end{array}$ & Reference \\
\hline Goat & FID & $\begin{array}{l}\text { WCOT silica capillary } \\
(50 \mathrm{~m} \times 0.22 \mathrm{~mm} \text { i.d. } \times 0.22 \mu \mathrm{m} \text { film thickness }) \\
\text { containing a Silar } 5 \mathrm{CP}(50 \% \text { phenyl, } 50 \% \text { cyanopropyl; } \\
\text { Chrompack, Middelburg, the Netherlands })\end{array}$ & C28-C54 & Fontecha et al., 2000 \\
\hline Sheep & MSD & $\begin{array}{l}\text { WCOT silica capillary } \\
(50 \mathrm{~m} \times 0.22 \mathrm{~mm} \text { i.d. } \times 0.22 \mu \mathrm{m} \text { film thickness }) \\
\text { containing a Silar } 5 \mathrm{CP}(50 \% \text { phenyl, } 50 \% \text { cyanopropyl; } \\
\text { Chrompack })\end{array}$ & C28-C54 & Fontecha et al., 2005 \\
\hline $\begin{array}{l}\text { Cow (adulterants: pork lard, } \\
\text { bovine tallow, fish oil, } \\
\text { peanut, corn, olive, soy) }\end{array}$ & FID & $\begin{array}{l}\text { Phenyl methyl silicon at } 5 \%, \\
\text { intermediate polarity HP5 }(2 \mathrm{~m} \times 0.25 \mathrm{~mm} \text { i.d. } \times 0.25 \\
\mu \mathrm{m} \text { film thickness; Agilent Technologies, Palo Alto, CA })\end{array}$ & C28-C54 & Gutiérrez et al., 2009 \\
\hline Cow, goat & FID & $\begin{array}{l}\text { Phenyl methyl silicon at } 5 \%, \text { intermediate polarity HP } 5 \\
(2 \mathrm{~m} \times 0.25 \mathrm{~mm} \text { i.d. } \times 0.25 \mu \mathrm{m} \text { film thickness; Agilent } \\
\text { Technologies })\end{array}$ & C28-C54 & Tolentino et al., 2015 \\
\hline
\end{tabular}

${ }^{1} \mathrm{FID}=$ flame ionization detector; MSD $=$ mass selective detector.

${ }^{2} \mathrm{WCOT}=$ wall-coated open tubular.

lem is lack of potential automation; therefore, research should move toward simplifying and miniaturizing sample preparation, scaling down the size of the system, or to developing new setups and techniques.

\section{DIRECT ANALYSIS METHODS OF TRIACYLGLYCEROLS}

\section{Analysis of Triacylglycerols by GC}

The application of GC for the analysis of TAG was reviewed in detail in the 1990s, because this technique was commonly used to analyze the molecular species of TAG prior to 1990. Generally, high-resolution GC (HRGC) with flame-ionization detection (FID) is widely used in food analysis to reveal the FA composition of TAG of vegetable (Cossignani et al., 2017; Blasi et al., 2018) and animal (Blasi et al., 2008; Cossignani et al., 2011) origin, but even today it is used by some researchers to analyze TAG molecular species (Tolentino et al., 2015; Bononi et al., 2017). Usually, GC is more suitable for detecting volatile and semivolatile compounds, but high-temperature GC is a valuable tool for determining molecular species of TAG, if appropriately used (Christie and Han, 2012).

Table 1 shows the GC methods published after 2000 for the determination of TAG in milk fat, with different stationary phases and detection systems (FID, MS). The most critical aspects of TAG separation by GC analysis were the low volatility of TAG, the possibility of pyrolysis at the high temperature required for elution, the thermal instability of TAG, especially for samples containing UFA, the injection and detection systems, and the nature of the stationary phase.

In terms of injection mode, the right choice can be of critical importance, and some reliable techniques have been used (Buchgraber et al., 2004): cold on-column injection (OCI), split injection, and programmed-temperature vaporizer injection systems (Fontecha et al., 2000; Bononi et al., 2017). For the detection system, FID is generally used and response factors for quantitative studies of TAG can be obtained using butter oil as reference (Kalo et al., 2004). Generally, a mixture of synthetic TAG is first analyzed to determine both the best chromatographic conditions and the retention times of these components, and then MS should be used for TAG identification. For the stationary phase, lowpolarity phases are most stable to high temperatures but only permit separation by TAG molecular weight. In contrast, modern high-polarity or polarizable phases in short capillary columns of fused silica offer remarkable separation, exhibiting resolution by both FA chain length (carbon number) and degree of unsaturation, but they are the least stable to high temperatures. Column manufacturers have tried to produce medium-polarity stationary phases with acceptable temperature stability (chemical bonding to the support and cross-linking of polymers) as a compromise to achieve an adequate degree of separation by both chain-length and degree of unsaturation (Christie and Han, 2012).

Table 2 shows the TAG composition of fat from cow, goat, sheep, donkey, camel, water buffalo, horse, and human milk, based on carbon number. A wide range of TAG variability can be noted among various mammali- 
Table 2. Percentage relative triacylglycerol composition (range: minimum and maximum of literature data ${ }^{1}$ ) of the milk fat of different origins

\begin{tabular}{|c|c|c|c|c|c|c|c|c|}
\hline $\begin{array}{l}\text { Carbon } \\
\text { number }\end{array}$ & Cow & Goat & Sheep & Donkey & Camel ${ }^{[b]}$ & $\begin{array}{l}\text { Water } \\
\text { buffalo }\end{array}$ & Horse $^{[\mathrm{b}]}$ & Human ${ }^{[a]}$ \\
\hline$\overline{\mathrm{C} 22}$ & $0.07^{[\mathrm{a}]}$ & ${ }^{2}$ & $0.06^{[\mathrm{a}]}$ & $0.01^{[\mathrm{a}]}$ & - & - & - & - \\
\hline $\mathrm{C} 24$ & $0.06^{[\mathrm{b}]}-0.56^{[\mathrm{a}]}$ & $0.08^{[\mathrm{b}]}-0.36^{[\mathrm{a}]}$ & $0.08^{[\mathrm{b}]}-0.65^{[\mathrm{a}]}$ & $0.09^{[\mathrm{b}]}-0.49^{[\mathrm{a}]}$ & 0.10 & 0.08 & 0.08 & 0.34 \\
\hline $\mathrm{C} 28$ & $0.45^{[\mathrm{c}]}-1.1^{[\mathrm{d}]}$ & $0.38^{[\mathrm{a}]}-0.78^{[\mathrm{b}]}$ & $0.86^{[\mathrm{b}]}-1.80^{[\mathrm{a}]}$ & $0.57^{[\mathrm{b}]}-0.65^{[\mathrm{a}]}$ & 0.01 & 0.75 & 0.51 & - \\
\hline C30 & $0.58^{[\mathrm{cc}]}-1.8^{[\mathrm{d}]}$ & $0.89^{[\mathrm{a}]}-1.69^{[\mathrm{b}]}$ & $1.57^{[\mathrm{b}]}-2.93^{[\mathrm{a}]}$ & $1.18^{[\mathrm{b}]}-1.65^{[\mathrm{a}]}$ & 0.03 & 1.30 & 1.04 & - \\
\hline C32 & $1.45^{[\mathrm{c}]}-3.6^{[\mathrm{d}]}$ & $1.72^{[\mathrm{a}]}-3.02^{[\mathrm{b}]}$ & $2.65^{[\mathrm{b}]}-4.35^{[\mathrm{a}]}$ & $1.53^{[\mathrm{b}]}-2.72^{[\mathrm{a}]}$ & 0.09 & 2.82 & 1.38 & - \\
\hline $\mathrm{C} 40$ & $9.21^{[\mathrm{e}]}-12.6^{[\mathrm{d}]}$ & $9.22^{[\mathrm{a}]}-12.14^{[\mathrm{b}]}$ & $11.08^{[\mathrm{b}]}-13.62^{[\mathrm{a}]}$ & $5.16^{[\mathrm{b}]}-7.82^{[\mathrm{a}]}$ & $\begin{array}{l}.04 \\
0.78\end{array}$ & $\begin{array}{r}10.00 \\
9.49\end{array}$ & 5.76 & $\begin{array}{l}1.11 \\
2.24\end{array}$ \\
\hline $\mathrm{C} 42$ & $6.17^{[\mathrm{a}]}-7.9^{[\mathrm{d}]}$ & $9.75^{[\mathrm{a}]}-11.14^{[\mathrm{b}]}$ & $7.97^{[\mathrm{b}]}-8.77^{[\mathrm{a}]}$ & $7.63^{[\mathrm{b}]}-10.15^{[\mathrm{a}]}$ & 1.80 & 5.77 & 8.86 & 4.26 \\
\hline $\mathrm{C} 44$ & $5.27^{[\mathrm{c}]}-7.63^{[\mathrm{e}]}$ & $9.86^{[\mathrm{b}]}-10.16^{[\mathrm{a}]}$ & $7.17^{[\mathrm{b}]}-7.25^{[\mathrm{a}]}$ & $10.55^{[\mathrm{b}]}-12.49^{[\mathrm{a}]}$ & 5.20 & 5.40 & 11.49 & 7.39 \\
\hline $\mathrm{C} 46$ & $5.2^{[\mathrm{d}]}-8.6^{[\mathrm{e}]}$ & $7.78^{[\mathrm{b}]}-10.02^{[\mathrm{a}]}$ & $6.40^{[\mathrm{a}]}-6.81^{[\mathrm{b}]}$ & $9.00^{[\mathrm{b}]}-9.83^{[\mathrm{a}]}$ & 12.48 & 6.68 & 10.41 & 11.17 \\
\hline $\mathrm{C} 48$ & $6.2^{[\mathrm{d}]}-10.09^{[\mathrm{e}]}$ & $7.08^{[\mathrm{b}]}-9.60^{[\mathrm{a}]}$ & $5.57^{[\mathrm{a}]}-7.38^{[\mathrm{b}]}$ & $6.90^{[\mathrm{a}]}-7.10^{[\mathrm{b}]}$ & 21.60 & 8.79 & 10.02 & 12.68 \\
\hline C50 & $8.4^{[\mathrm{d}]}-13.43^{[\mathrm{c}]}$ & $8.22^{[\mathrm{b}]}-11.75^{[\mathrm{a}]}$ & $6.81^{[\mathrm{a}]}-9.66^{[\mathrm{b}]}$ & $8.76^{[\mathrm{a}]}-11.43^{[\mathrm{b}]}$ & $\begin{array}{l}21.00 \\
25.79\end{array}$ & $\begin{array}{r}0.19 \\
10.52\end{array}$ & $\begin{array}{l}10.02 \\
13.19\end{array}$ & $\begin{array}{l}12.00 \\
17.79\end{array}$ \\
\hline
\end{tabular}

${ }^{1}$ Sources: [a] = Bononi et al., 2017; [b] = Smiddy et al., 2012; [c] = Gutiérrez et al., 2009; [d] = Taylor and MacGibbon, 2011; [e] = TzompaSosa et al., 2016.

${ }^{2}$ Not reported.

an species; for example, C52 is a TAG more represented in donkey milk (16.22-21.01\%) than in other milks (cow, goat, sheep), where the main TAG are C38 and C40 (around 20\% expressed as total). These compositions, although variable, could be used as biomarkers - useful fingerprints of milk origin. For the practical application of these markers, analysis of a large number of samples could be used to build a database to compare samples of unknown animal origin. It can be seen that some other milks (horse, camel) are less extensively studied and thus more research is necessary.

Interestingly, Gutiérrez et al. (2009) analyzed adulterated samples (cow milk with $5,10,15$, or $20 \%$ added nonmilk fat) by GC-FID and identified samples by linear discriminant analysis (LDA) based on 3 carbon number variables (C36, C48, and C52). They developed an effective method of detecting adulteration at levels $<10 \%$, and their results assisted in creation of a proposal for a national norm to verify milk fat authenticity in milk and dairy products.

Smiddy et al. (2012), following ISO standard 17678:2010/IDF 202:2010 (ISO, 2010b), separated TAG molecular species of milks from different mammalian species (horse, cow, sheep, goat, donkey, camel, and water buffalo) by GC. The TAG composition data were analyzed by principal component analysis for the classification, but better discrimination was obtained when differential scanning calorimetry data were also considered. Cow milk samples, as well as some sheep and buffalo water milk samples, showed generally higher concentrations of C50, C52, and C54 TAG. Mostly goat milk samples had higher concentrations of C40, C42, and C44 TAG. The method proposed by Smiddy et al. (2012) has some practical limits; in fact, because of the low fat content of horse, camel, and donkey milks, it is not applicable for use in these species.

The ISO procedure 17678:2010/IDF 202:2010 (ISO, $2010 \mathrm{~b}$ ) is the reference method for the detection of foreign fats; both vegetable and animal fats (beef tallow and lard) can be detected in the milk fat of dairy products using GC analysis of TAG and defined TAG equations. The method is independent of the variation in common feeding practices, breed or lactation conditions, but excludes some products, such as cheese, because the ripening process can affect the fat composition and yield a false-positive result (Molkentin and Precht, 2000).

More recently, Bononi et al. (2017) proposed a HRGC-OCI method and obtained a clear differentiation between different species of milk (cow, donkey, human, sheep, and goat). Figure 1 shows the typical HRGCOCI profile produced for the fat fraction of cow milk expressed as total carbon number (TCN), from C22 to C54. The profile, if compared with other more expensive milks, demonstrates a clear differentiation between different species of milks (donkey, human, cow, sheep, and goat), and the TAG pattern may be considered a fundamental characteristic of milk from each species. For example, the donkey milk profile is characterized by TAG classes with TCN below 34, whereas human milk is characterized by TAG classes with TCN greater than 40. The proposed HRGC-OCI method produces 


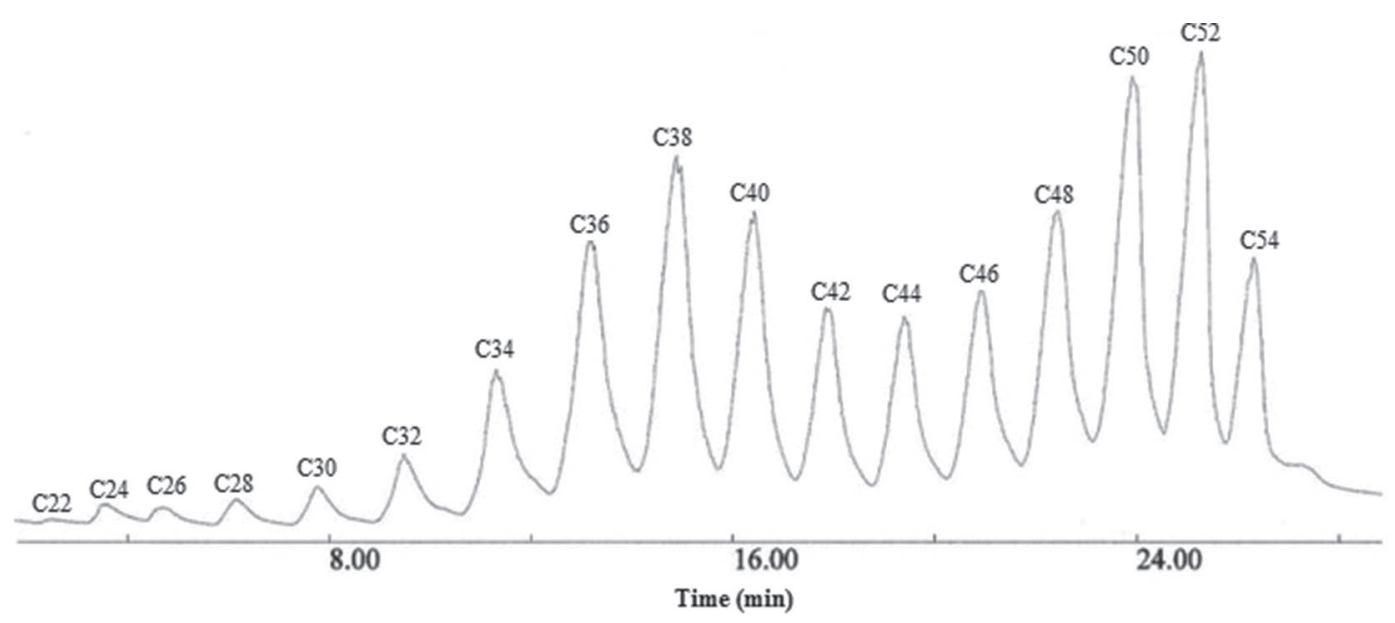

Figure 1. High-resolution gas chromatography on-column injection (HRGC-OCI) profile produced for fat fraction of cow milk expressed as total carbon number. Adapted with permission from Bononi et al. (2017).

reproducible results and permits easy characterization and practical comparison, making it useful for industrial quality control of milk.

\section{Analysis of Triacylglycerols by Liquid Chromatography}

The separation of TAG molecular species by HPLC is the most widely used method today. Although time consuming, sample cleaning or fractioning by SPE columns or thin-layer chromatography (TLC) before LC-MS analysis can often facilitate lipid species identification and improve the quality of lipidomics data. Table 3 shows methods published after 2000 for the determination of TAG in milk fat using HPLC methods, with different detection systems and different stationary and mobile phases.

For TAG characterization, reversed-phase liquid chromatography (RPLC) has generally been used, together with silver ion chromatography $\left(\mathbf{A g}^{+}-\mathbf{H P L C}\right)$.

The RPLC achieves separation based on TAG hydrophobicity; the elution order depends on the acyl chain length and the number of double bonds. The TAG molecular species are eluted according to the partition number $(\mathbf{P N})$, also called equivalent carbon number $(\mathbf{E C N})$ :

$$
\mathrm{PN}(\text { or } \mathrm{ECN})=\mathrm{TCN}-2 \times \mathrm{DBN},
$$

where TCN is the total carbon number and DBN is the number of double bonds in TAG molecules. In this case, elution time increases with PN; it should be noted that LC separation is able to resolve TAG groups with different ECN but cannot generally resolve groups with the same ECN.
Generally, using reverse phase columns, TAG groups with only one double bond less are adequately resolved, but some commonly used MS analyzers are unable (if the resolving power $<100,000)$ to differentiate the $\mathrm{M}+2$ isotope of one group with the monoisotopic mass of another group. However, today's MS analyzers, such as time of flight (TOF), Fourier transform-ion cyclotron resonance (FT-ICR), and Orbitrap, have a resolution of 500,000 to 1,000,000. This technical evolution should greatly facilitate the identification of TAG groups in milk samples. Although atmospheric pressure chemical ionization-mass spectrometry (APCI-MS) has been widely used for TAG characterization (Mottram and Evershed, 2001; Gastaldi et al., 2011; Beccaria et al., 2014), electrospray ionization-mass spectrometry (ESI-MS) is more versatile (Li et al., 2017, 2018) and thus more popular in comprehensive lipidomic analysis.

As documented in many research papers (Mottram and Evershed, 2001; Gastaldi et al., 2011; Ten-Doménech et al., 2015), the LC technique, performed under non-aqueous reversed-phase (NARP) conditions, is by far the most-used technique to attain detailed information on TAG composition in natural samples.

Mottram and Evershed (2001) reported for the first time the identification of 120 intact TAG species in whole milk fat by using HPLC-APCI-MS, preceded by TLC and gel permeation chromatography for milk fat fractioning. The proposed method was time consuming and laborious, and therefore not suitable for daily applicability in routine quality control. In contrast, Gastaldi et al. (2011) used NARP-HPLC-APCI MS/MS without pre-fractionation. They found that in mature bovine milk, the most abundant TAG groups included TAG with an even number of carbon atoms (from C34:0 to C40:0 and C48:0), TAG with one unsaturation (38:1, 
COSSIGNANI ET AL.

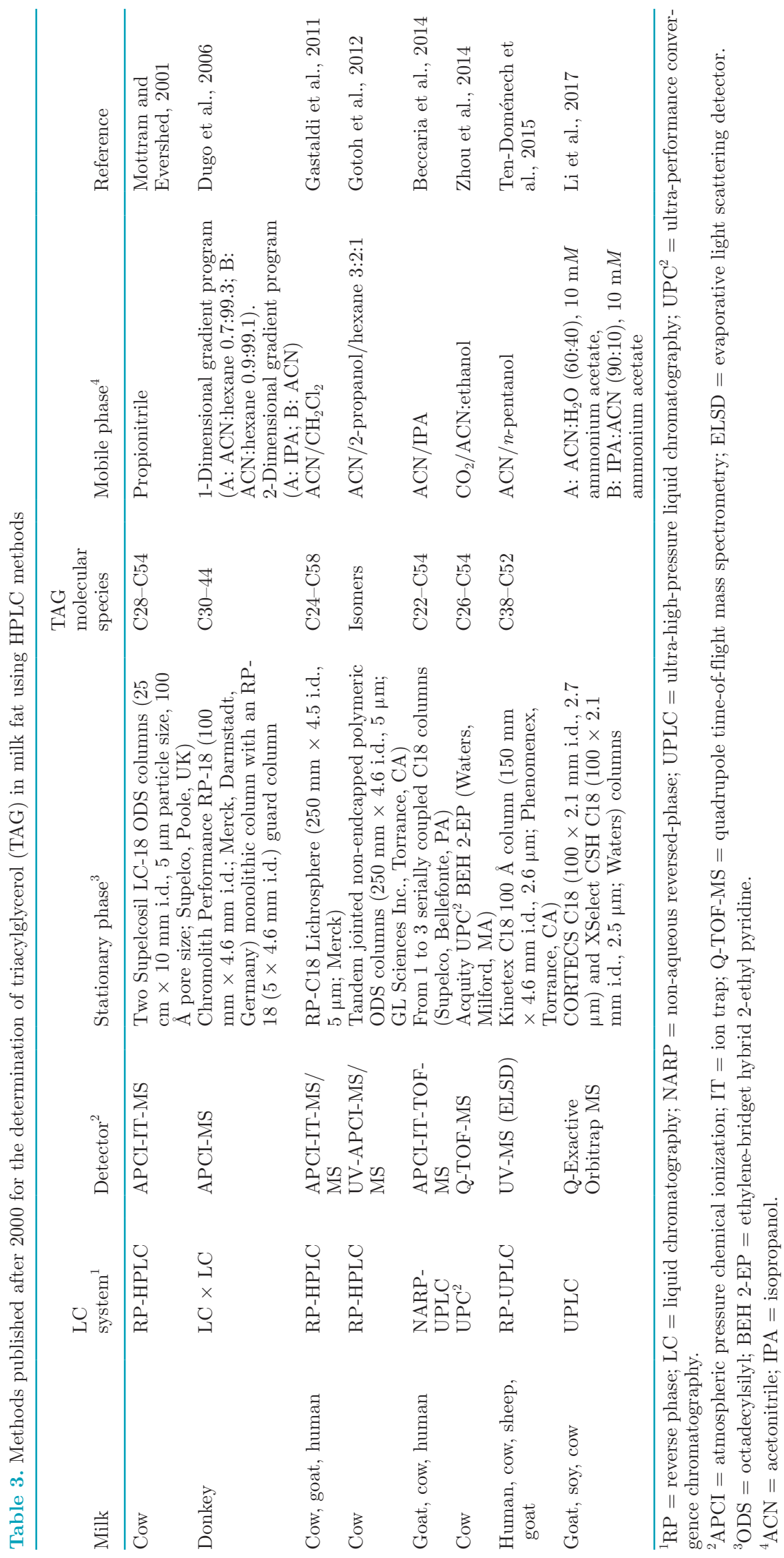


40:1, 46:1, 50:1, 52:1) and TAG with 2 unsaturations (C50:2, 52:2). The relatively large amount (>40\%) of TAG with a TCN $<40$ was due to the presence of short-chain FA (C4:0-C8:0) in bovine milk. This is a distinctive feature of bovine milk and useful to distinguish it from other milks (goat and human milks) for authentication. Moreover, Gastaldi et al. (2011) investigated the TAG composition of n-3-enriched cow milk and found some differences in TAG species containing docosahexaenoic acid (DHA) in respect to human milk. In fact, 10 TAG species containing DHA were identified in human milk, whereas only one, of different composition, was identified in n-3-enriched milk. It can be assumed that TAG containing DHA could be a valid marker to distinguish human milk from n-3-enriched cow milk.

More recently, Ten-Doménech et al. (2015) performed an RP-HPLC optimization study, using a core-shell particle-packed column with UV and evaporative light scattering detectors and developed a statistical study based on LDA of TAG composition data of different types of milks (human, cow, sheep, and goat) to differentiate the samples according to their mammalian origin, by using some peak area TAG ratios. Because of the marked differences between cow and goat milks, the method is applicable to the authentication of these 2 types of milks; discrimination between sheep and human milks was not possible.

Separation of regioisomers $(\beta-\mathrm{PPC} / \beta-\mathrm{PCP}, \beta-\mathrm{PPO} /$ $\beta$-POP, $\beta$-POO $/ \beta$-OPO, and $\beta$-PPD $/ \beta$-PDP, where $\mathrm{P}$ $=$ palmitic, $\mathrm{C}=$ capric, $\mathrm{O}=$ oleic, and $\mathrm{D}=$ docosahexaenoic acids) was performed by LC/APCI-MS/MS for TAG of cow milk (Gotoh et al., 2012). The ratio $\beta$-OPO $/ \beta$-POO in milk TAG of ruminant animals was opposite of that in nonruminant milks, whereas $\beta$-PPO was the main regioisomer in both categories. These differences are useful for authentication of fat, but the main disadvantage of the method lies in the fact that the $s n-1$ and $s n-3$ positions cannot be distinguished. Moreover, instead of milk fat, the authors used cow, buffalo, goat and sheep cheese fat; therefore, the practical applicability of the method for the purposes of milk authentication is questionable (Gotoh et al., 2012).

To improve the LC separation capability afforded by a single column (Liu et al., 2018), some researchers have used serially coupled columns (Mottram and Evershed, 2001; Beccaria et al., 2014). Three core-shell type C18 columns in series have been used to separate, in 150 min, 243 different TAG (Figure 2), unambiguously identified by APCI-ion trap-TOF-MS (Beccaria et al., 2014). In fact, NARP-LC with serially coupled columns is probably the best-known method for separating TAG isomer species of the same group or same ECN.
Although 1-dimensional chromatographic techniques have proved to be very useful for the elucidation of milk TAG profiles, a fully comprehensive analytical view of these samples can be attained by using on-line multidimensional-LC systems, which are based on the combination of 2 independent separation steps with orthogonal selectivity (Dugo et al., 2006). These authors separated 57 TAG molecular species of donkey milk by using comprehensive 2-dimensional liquid chromatography $(\mathrm{LC} \times \mathrm{LC})$, based on the combination of $\mathrm{Ag}^{+}-$ HPLC and RP-HPLC, with APCI-MS detection. The proposed method (Dugo et al., 2006) was an effective tool for the characterization of donkey milk, but not for the detection of fraud relative to the undeclared addition of other cheaper milks.

In $\mathrm{Ag}^{+}$-HPLC, the stationary phase consists of an ion-exchange medium loaded with silver ions. Generally, the separation of FA is based primarily on the
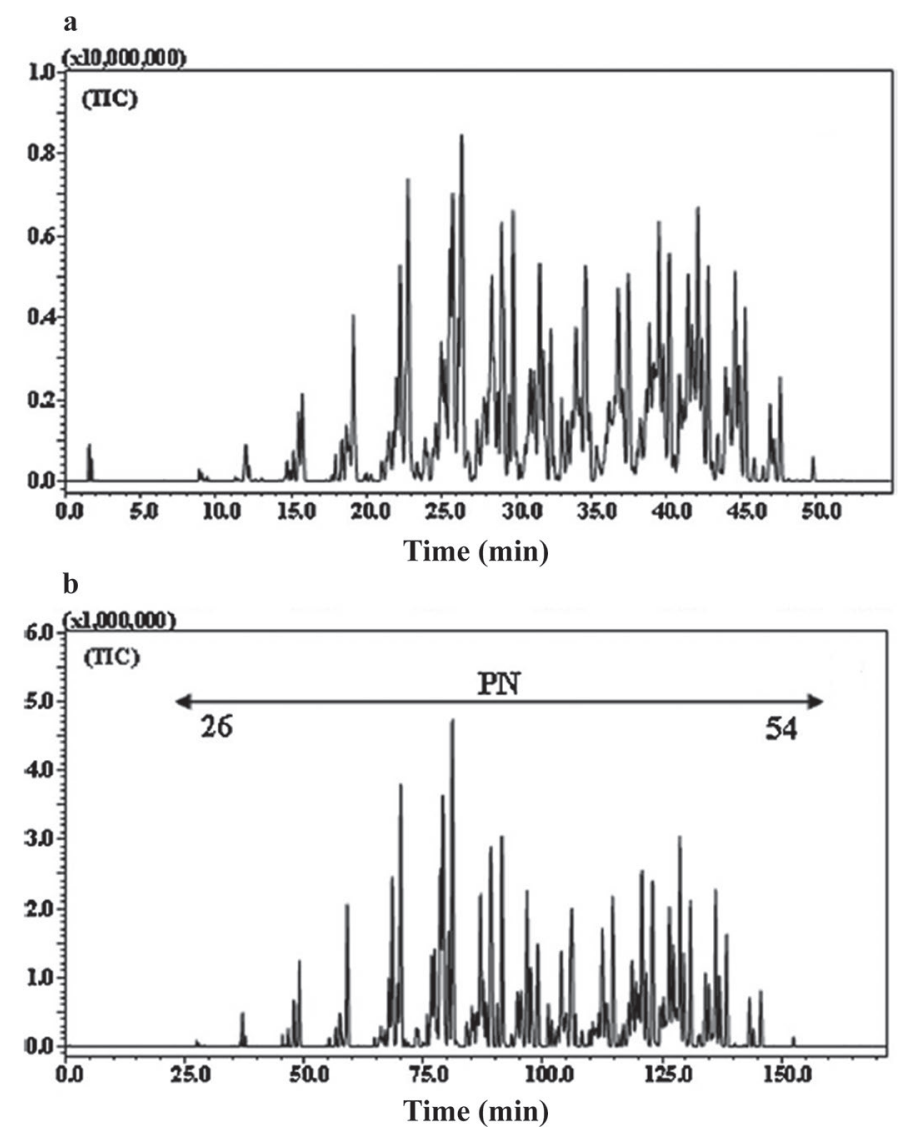

Figure 2. Total ion current (TIC) chromatograms of the nonaqueous reversed-phase (NARP) liquid chromatography-atmospheric pressure chemical ionization (APCI)-MS for cow milk analyzed on 1 Ascentis Express C18 column (top; Sigma-Aldrich, Milan, Italy) and 3 serially coupled Ascentis Express C18 columns (bottom), showing partition number $(\mathrm{PN})$ or equivalent carbon number. Adapted from Beccaria et al. (2014) with permission from Elsevier. 
interaction of $\pi$ electrons of double bonds of acyl chains with electrons in $d$ orbitals of silver ions, but the retention mechanism could be explained with different interaction types (Nikolova-Damyanova, 2009).

Compared with RP-HPLC, $\mathrm{Ag}^{+}$-HPLC often provides much simpler chromatograms of TAG. It is considered a necessary step in the sequence of chromatographic methods needed to resolve a complex lipid mixture into simpler molecular species. The sequential application of $\mathrm{Ag}^{+}$-HPLC and RP-HPLC for the analysis of TAG in complex lipid samples outperforms either of these techniques applied singly. Triacylglycerols have been separated according to the overall number of double bonds in the molecule, even if TAG retention is also affected by the distribution of double bonds in acyl groups (Nikolova-Damyanova, 2009). Silver ion-HPLC has also been used for FA separation, such as complex mixture of CLA isomers (Delmonte et al., 2005; Cossignani et al., 2013).

High-resolution accurate mass LC/MS (HRAM LC/MS) shows potential for monitoring dairy product quality. Hrbek et al. (2014) first extracted TAG from cow, goat, and sheep milks with toluene, and then analyzed the species-specific TAG profiles by direct analysis in real time (DART)-HRAM LC/MS under positivemode DART ionization. Reliable differentiation of cow milk and goat or sheep milk is possible using LDA, but the proposed technique showed good discrimination only when the goat or sheep milk was diluted with cow milk at levels of $50 \%$ ( $\mathrm{vol} / \mathrm{vol}$ ). The sensitivity of the proposed method was much higher when vegetable oils (rapeseed, sunflower, and soybean) were added to soft cheese at levels as low as 1\% (wt/wt). For this last result, the proposed procedure could find practical applicability.

Li et al. (2017) obtained lipidomics profiling of goat milk, soymilk, and bovine milk by ultra-performance liquid chromatography (UPLC) coupled with Orbitrap MS, and acquired, in positive ionization mode, 300 species of TAG. High amounts of TAG were found in bovine milk with a higher content of medium-chain triglycerides (MCT) compared with goat milk. Bovine milk is also rich in ceramides and DAG, unlike the other milks. The authors identified different lipid components as biomarkers (among which DHA, MCT, and TAG) for differentiation of milk types, highlighting the potential of the developed method for milk authentication.

As an alternative method to LC-MS and GC-MS, supercritical fluid chromatography (SFC) is a promising analytical technique, with several advantages, such as environmentally friendly, low cost, faster separation, and better resolution, particularly for nonpolar and with low-polarity compounds. With the introduction of a new generation of SFC - ultra-performance convergence chromatography (UPC ${ }^{2}$ - analytical time and the use of organic solvent could be drastically reduced, which makes its application in routine or high-throughput analysis more attractive. The most complete chemical profiling of TAG (and DAG) in cow milk fat was carried out for the first time by Zhou et al. (2014) with an environmentally friendly UPC ${ }^{2}$-QTOF-MS approach, without an additional sample pretreatment. Thus, QTOF-MS may serve as a powerful tool in unequivocally identifying chemical compositions of foods because of its excellent ability to provide accurate mass data and $\mathrm{MS}^{2}$ fragment ion patterns. This approach might have a future in lipidomics studies for TAG analysis in food or biological samples.

Generally, the recently proposed methods (UPC ${ }^{2}-$ QTOF-MS; UPLC-Orbitrap MS) represent powerful tools for complete analytical characterization but they are not useful for routine quality control, because of the high cost of the instrumentation, management, and use.

\section{INDIRECT ANALYSIS FOR TRIACYLGLYCEROL STRUCTURE DETERMINATION}

A deep understanding of TAG structure is of great importance for the nutritional and technological properties of fats. Moreover, the qualitative and quantitative profiles of TAG molecular species derive from the enzymatic specificity of the biosynthetic process; it represents a fingerprint of origin species, useful for product authentication. It is known that the FA distribution among the 3 sn positions of the glycerol backbone is nonrandom, in both vegetable (Montesano et al., 2018) and animal foods, including milk of various species (Blasi et al., 2008, 2013).

Indirect TAG analysis methods allow FA positional composition and qualitative and quantitative analyses of all molecular TAG species, including enantiomeric isomers. Regiospecific analysis of TAG can be obtained by the enzymatic reaction catalyzed by porcine pancreatic lipase (EC 3.1.1.3; Christie and Han, 2012) or by Grignard chemical deacylation. The latter procedure is the preferred method for the analysis of milk TAG, because it does not show acylic specificity (Turon et al., 2002; Tzompa-Sosa et al., 2014). It allows the direct determination of FA composition of $s n-2$ position and the differentiation of FA esterified in the primary $(s n-1,3)$ and secondary ( $s n-2)$ position of the glycerol backbone. This approach is based on 1,3 random, 2-random distribution theory (RR procedure).

In TAG regiospecific analysis, sn-2-monoacylglycerols (sn-2-MAG), obtained by enzymatic hydrolysis or chemical deacylation, are isolated by a preparative TLC and transesterified as FAME for the subsequent 
GC-FID. It allows the determination of the FA composition (\%) in the $s n$-2-position of the native TAG. The FA composition in the $s n-1(3)$ positions can then be estimated from the composition of the $s n-2-\mathrm{MAG}$ and TAG, according to the following formula:

$$
\mathrm{A} 1,3=\frac{[3 \times \mathrm{At}-\mathrm{A} 2]}{2},
$$

where A1,3 $=\%$ FA in $s n-1$ and $s n-3$ positions; At $=\%$ FA in total TAG; A2 $=\%$ FA in $s n-2$ position.

Regiospecific analysis is of great relevance from a nutritional point of view; in fact, FA esterified in $s n-2$ position are highly bioavailable because $s n-2-\mathrm{MAG}$ are completely absorbed and re-esterified in the enterocytes. Moreover, FA compositions in $s n-1$ and $s n-3$ are equally important for a full characterization of TAG fraction, being related to enzymatic specificity of the biosynthetic processes.

Complete characterization of TAG molecular species structure can be obtained by stereospecific analysis, based on the 1 random, 2 random, 3 random distribution theory (the RRR procedure), that considers the distribution of FA random and different in the 3 sn positions. To this aim, the analytical approaches are based on enzymatic-instrumental and chemical-instrumental procedures. As regards enzymatic stereospecific analysis, the procedure of $s n-1,2$ diacylglycerol kinase is more suitable for stereospecific analysis of vegetable fat (Christie and Han, 2012), whereas the most suitable for milk TAG, containing FA with short length chain, is the phospholipase $\mathrm{A}_{2}$ procedure (Figure 3 ).

The percent FA compositions of $s n-1$ and $s n-2$ positions can be obtained, respectively, after HRGC-FID analysis of the FAME of hydrolysis products (sn1-lysophosphatidylcholine and free FA). The percent
FA composition of $s n-3$ position can be calculated by applying the following formula:

$$
\mathrm{A} 3=[3 \times \mathrm{At}-\mathrm{A} 2-\mathrm{A} 1]
$$

where $\mathrm{A} 3=\% \mathrm{FA}$ in $s n-3$ position; At $=\% \mathrm{FA}$ in total $\mathrm{TAG} ; \mathrm{A} 2=\% \mathrm{FA}$ in $s n-2$ position; $\mathrm{A} 1=\% \mathrm{FA}$ in $s n-1$ position.

The most complete characterization of TAG by stereospecific analysis of donkey, cow, ewe, goat and buffalo milks, carried out using the phospholipase $\mathrm{A}_{2}$ (EC 3.1.1.4) procedure, was obtained by Blasi et al. (2008). The main disadvantage of these methods is that they are time consuming and not applicable for routine quality control, even if a total complete characterization of regioisomers and enantiomers can be obtained.

Table 4 shows total and positional FA percent composition of cow milk TAG (determined with stereospecific and regiospecific procedures). Palmitic, oleic, and linoleic acids were, respectively, the most abundant SFA, MUFA, and PUFA. Generally, the $s n-1$ and $s n-2$ positions were mainly esterified by palmitic acid, whereas short FA, such as butyric, caproic, and caprylic acids, preferred the $s n-3$ position. The PUFA, present in relatively low concentrations, preferred primary positions. The different FA distribution over the $3 s n$ positions for different types of milks is important for authentication, because it is species-specific. For example, as regards the FA composition of $s n-2$ position, ewe milk shows the highest content of oleic acid, whereas donkey milk shows the lowest content of palmitic acid and different from cow milk. In goat and donkey milks, the main FA esterified in the $s n-3$ position is capric acid, whereas in ewe milk it is butyric acid (Blasi et al., 2008). These differences become important discriminant parameters during LDA; in fact, it is possible to correctly discrimi-

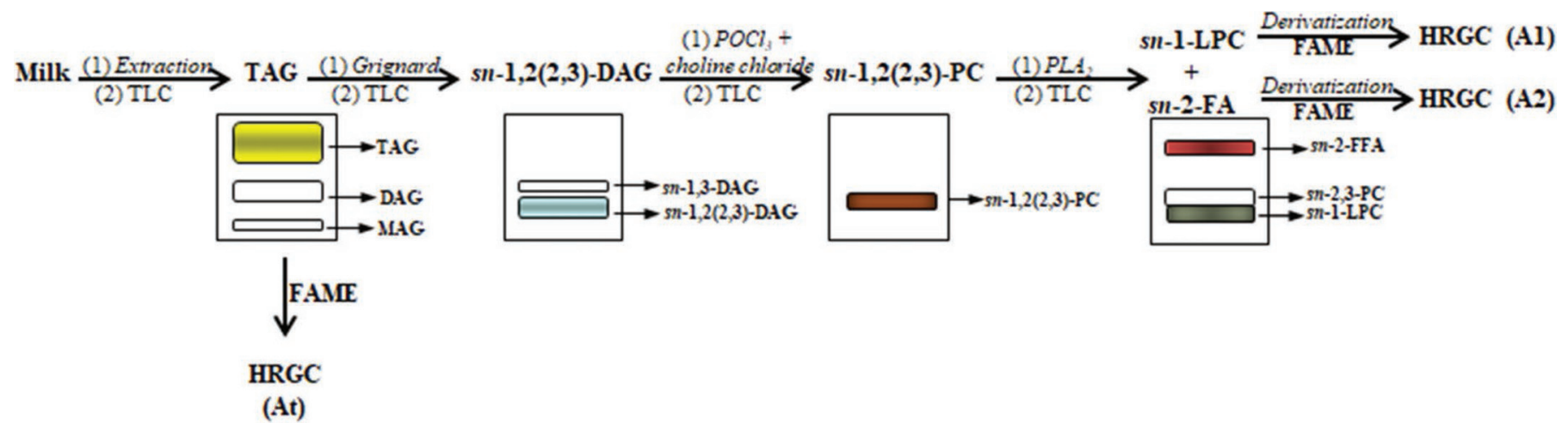

Figure 3. Scheme of the stereospecific procedure of phospholipase $\mathrm{A}_{2}\left(\mathrm{PLA}_{2}\right)$. The triacylglycerol (TAG) fraction is subjected to partial deacylation using the Grignard reaction following extraction and thin-layer chromatography (TLC). The obtained mixture of $s n-1,2(2,3)$ diacylglycerol (DAG) isomers is converted to $s n-1,2(2,3)$-diacyl-phosphatidylcholines (PC), which is hydrolyzed by PLA 2 (EC 3.1.1.4) to obtain $s n$-1-lysophosphatidylcholine ( $s n$-1-LPC) and free $s n$-2-FA. These products, derivatized as FAME, give, respectively, the $s n-1$ (A1) and $s n-2$ (A2) fatty acid (FA) compositions by high-resolution (HR)GC. At = percent FA in total TAG; MAG = monoacylglycerol. 
Table 4. Total and positional fatty acid composition (\%) of cow milk triacylglycerol (TAG; determined with stereospecific ${ }^{[\mathrm{a}]}$ and regiospecific ${ }^{[\mathrm{b}, \mathrm{c}]}$ procedures $^{1}$ )

\begin{tabular}{|c|c|c|c|c|c|}
\hline $\begin{array}{l}\text { Fatty } \\
\text { acid }^{2}\end{array}$ & TAG & $s n-2$ & $s n-1{ }^{[\mathrm{a}]}$ & $s n-3^{[\mathrm{a}]}$ & $s n-1(3)$ \\
\hline$\overline{\mathrm{C} 4: 0}$ & $6.0^{[\mathrm{a}]}-9.4^{[\mathrm{b}]}$ & $0.4^{[\mathrm{a}]}$ & 1.3 & 17.9 & $10.2^{[\mathrm{c}]}-17.5^{[\mathrm{c}]}$ \\
\hline C6:0 & $2.9^{[\mathrm{a}]}-4.45^{[\mathrm{b}]}$ & $0.2^{[\mathrm{b}]}-0.9^{[\mathrm{a}]}$ & 0.3 & 8.2 & $5.5^{[\mathrm{c}]}-7.4^{[\mathrm{c}]}$ \\
\hline C8:0 & $1.7^{[\mathrm{a}]}-2.15^{[\mathrm{b}]}$ & $0.2^{[\mathrm{a}]}-2.9^{[\mathrm{c}]}$ & 0.3 & 4.7 & $2.0^{[\mathrm{c}]}-3.3^{[\mathrm{c}]}$ \\
\hline C10:0 & $3.4^{[\mathrm{a}]}-3.88^{[\mathrm{b}]}$ & $1.4^{[\mathrm{a}]}-7.8^{[\mathrm{c}]}$ & 1.1 & 8.7 & $3.0^{[\mathrm{c}]}-4.52^{[\mathrm{b}]}$ \\
\hline $\mathrm{C} 12: 0$ & $3.9^{[\mathrm{a}]}-4.61^{[\mathrm{b}]}$ & $4.8^{[\mathrm{a}]}-8.1^{[\mathrm{c}]}$ & 2.5 & 5.1 & $3.0^{[\mathrm{c}]}-4.46^{[\mathrm{b}]}$ \\
\hline C14:0 & $11.31^{[\mathrm{b}]}-13.1^{[\mathrm{a}]}$ & $16.73^{[\mathrm{b}]}-23.0^{[\mathrm{c}]}$ & 11.7 & 8.2 & $8.0^{[\mathrm{c}]}-10.2^{[\mathrm{c}]}$ \\
\hline C14:1 & $1.34^{[\mathrm{b}]}$ & $0.34^{[\mathrm{b}]}$ & 3 & - & $1.85^{[\mathrm{b}]}$ \\
\hline C15:0 & $1.11^{[\mathrm{b}]}$ & $0.9^{[\mathrm{b}]}$ & - & - & $1.21^{[\mathrm{b}]}$ \\
\hline C16:0 & $27.90^{[\mathrm{b}]}-31.6^{[\mathrm{a}]}$ & $32.0^{[\mathrm{c}]}-44.1^{[\mathrm{a}]}$ & 46.8 & 12.0 & $19.5^{[\mathrm{c}]}-28.0^{[\mathrm{c}]}$ \\
\hline C16:1 & $1.24^{[\mathrm{b}]}-0.8^{[\mathrm{a}]}$ & $0.49^{[\mathrm{b}]}-2.5^{[\mathrm{a}]}$ & 1.5 & 1.9 & $1.62^{[\mathrm{b}]}$ \\
\hline C18:0 & $6.6^{[\mathrm{a}]}-7.41^{[\mathrm{b}]}$ & $3.0^{[\mathrm{c}]}-11.47^{[\mathrm{b}]}$ & 11.1 & 5.2 & $5.36^{[\mathrm{b}]}-11.9^{[\mathrm{c}]}$ \\
\hline C18:1 & $17.05^{[\mathrm{b}]}-19.2^{[\mathrm{a}]}$ & $7.2^{[\mathrm{c}]}-19.0^{[\mathrm{c}]}$ & 21.5 & 25.1 & $14.6^{[\mathrm{c}]}-26.5^{[\mathrm{c}]}$ \\
\hline C18:2 & $1.9^{[\mathrm{a}]}$ & $0.6^{[\mathrm{c}]}-4.0^{[\mathrm{c}]}$ & 1.7 & 2.7 & $0.4^{[\mathrm{c}]}-2.0^{[\mathrm{c}]}$ \\
\hline C18:3 & $0.2^{[\mathrm{a}]}$ & $0.2^{[\mathrm{a}]}$ & 0.2 & 0.3 & - \\
\hline
\end{tabular}

${ }^{1}$ Sources: [a] = Blasi et al., 2008; [b] = Tzompa-Sosa et al., 2014; [c] = Turon et al., 2002.

${ }^{2} \mathrm{C} 4$ :0, butyric acid; C6:0, caproic acid; C8:0, caprylic acid; C10:0, capric acid; C12:0, lauric acid; C14:0, myristic acid; C14:1, cis-5-tetradecenoic acid; C15:0, pentadecanoic acid; C16:0, palmitic acid; C16:1, cis-9-hexadecenoic acid; C18:0, stearic acid; C18:1, oleic acid; C18:2, linoleic acid; C18:3, $\alpha$-linolenic acid.

${ }^{3}$ Not reported.

nate donkey or ewe milk mixed with $1 \%$ cow milk, because total and intrapositional TAG compositions are related to the stereospecific biosynthetic pathway (Cossignani et al., 2011; Blasi et al., 2013). The proposed method, using a larger sampling, could have practical application for the classification and authentication of unknown mixtures or samples. Another interesting application of enzymatic-instrumental methods is the monitoring of the synthesis of structured lipid to obtain better healthy fats; for example, producing TAG with CLA esterified in the $s n-2$ position, with nutritional advantages because of their real bioavailability or MCT useful for enteral nutrition (Blasi et al., 2009; Maurelli et al., 2009 a,b).

As regards chemical-instrumental methods for TAG stereospecific analysis, a possible approach is based on the application of chiral HPLC to separate derivatized enantiomers. Unfortunately, only a few older papers report this approach applied to the analysis of milk. For example, dinitrophenylurethane (DNPU) derivatives of the 1,2(2,3)-diacyl-rac-glycerol were resolved by chiralphase HPLC into 1,2-diacyl-sn-glycerol DNPU and 2,3-diacyl-sn-glycerol DNPU derivatives, before HRGC analysis of their constitutive FA moieties, to obtain a complete stereospecific determination of CLA in TAG of milk-fat (Valeille and Martin, 2004).

\section{CONCLUSIONS}

This review highlights the fact that most papers on milk TAG refer to pure milk samples, without considering possible blends and lacking a reliable chemometric approach to classify, differentiate, and authenticate milk samples. Moreover, the sensitivity of an analytical method is often not declared, making it difficult to evaluate the amount of adulterating milk added and, thus, to obtain a practical application of the method. The most common methods for TAG analysis are direct procedures, mainly based on HPLC. When using these methods, correction factors should be used to better estimate the proportion of the different TAG in milk fat. In recent years, advances in analytical techniques have improved TAG species resolution by using serially coupled columns or multi-dimensional chromatography. The current availability of MS analyzers with high resolving power greatly facilitates TAG molecule identification. Important progress has been made in the last 10 years in the analysis of lipid molecular species, but further advances in milk lipidomics are necessary for authentication and fraud evaluation.

\section{REFERENCES}

Abbas, O., M. Zadravec, V. Baeten, T. Mikuš, T. Lešićd, A. Vulićd, J. Prpiće, L. Jemeršiće, and J. Pleadin. 2018. Analytical methods used for the authentication of food of animal origin. Food Chem. 246:6-17. https://doi.org/10.1016/j.foodchem.2017.11.007.

AOAC International. 2016. Official Methods of Analysis. 20th ed AOAC International, Washington, DC.

Beccaria, M., G. Sullini, F. Cacciola, P. Donato, P. Dugo, and L. Mondello. 2014. High performance characterization of triacylglycerols in milk and milk-related samples by liquid chromatography and mass spectrometry. J. Chromatogr. A. 1360:172-187. https://doi .org/10.1016/j.chroma.2014.07.073.

Blasi, F., G. Lombardi, P. Damiani, M. S. Simonetti, L. Giua, and L. Cossignani. 2013. Triacylglycerol stereospecific analysis and linear discriminant analysis for milk speciation. J. Dairy Res. 80:144151. https://doi.org/10.1017/S0022029912000635. 
Blasi, F., S. Maurelli, L. Cossignani, G. D'Arco, M. S. Simonetti, and P. Damiani. 2009. Study of some experimental parameters in the synthesis of triacylglycerols with CLA isomers and structural analysis. J. Am. Oil Chem. Soc. 86:531-537. https://doi.org/10 .1007/s11746-009-1390-7.

Blasi, F., D. Montesano, M. De Angelis, A. Maurizi, F. Ventura, L. Cossignani, M. S. Simonetti, and P. Damiani. 2008. Results of stereospecific analysis of triacylglycerol fraction from donkey, cow, ewe, goat and buffalo milk. J. Food Compos. Anal. 21:1-7. https:/ /doi.org/10.1016/j.jfca.2007.06.005.

Blasi, F., D. Montesano, M. S. Simonetti, and L. Cossignani. 2017. A simple and rapid extraction method to evaluate the fatty acid composition and nutritional value of goji berry lipid. Food Anal. Methods 10:970-979. https://doi.org/10.1007/s12161-016-0652-x.

Blasi, F., G. Rocchetti, D. Montesano, L. Lucini, G. Chiodelli, S. Ghisoni, G. Baccolo, M. S. Simonetti, and L. Cossignani. 2018. Changes in extra-virgin olive oil added with Lycium barbarum L. carotenoids during frying: Chemical analyses and metabolomics approach. Food Res. Int. 105:507-516. https://doi.org/10.1016/j .foodres.2017.11.061.

Bligh, E. G., and W. J. Dyer. 1959. A rapid method of total lipid extraction and purification. Can. J. Biochem. Physiol. 37:911-917.

Bononi, M., F. Tateo, and A. Tateo. 2017. Triglycerides variability in donkey milk. Ital. J. Food Sci. 29:233-242.

Buchgraber, M., F. Ulberth, and E. Anklam. 2004. Interlaboratory evaluation of injection techniques for triglyceride analysis of cocoa butter by capillary gas chromatography. J. Chromatogr. A. 1036:197-203. https://doi.org/10.1016/j.chroma.2004.03.011.

Calvano, C. D., C. De Ceglie, A. Aresta, L. A. Facchini, and C. G. Zambonin. 2013. MALDI-TOF mass spectrometric determination of intact phospholipids as markers of illegal bovine milk adulteration of high-quality milk. Anal. Bioanal. Chem. 405:1641-1649. https://doi.org/10.1007/s00216-012-6597-z.

Castro-Gómez, M. P., L. M. Rodriguez-Alcalá, M. V. Calvo, J. Romero, J. A. Mendiola, E. Ibañez, and J. Fontecha. 2014. Total milk fat extraction and quantification of polar and neutral lipids of cow, goat, and ewe milk by using a pressurized liquid system and chromatographic techniques. J. Dairy Sci. 97:6719-6728. https:// doi.org/10.3168/jds.2014-8128.

Cequier-Sánchez, E., C. Rodríguez, A. G. Ravelo, and R. Zárate. 2008. Dichloromethane as a solvent for lipid extraction and assessment of lipid classes and fatty acids from samples of different natures. J. Agric. Food Chem. 56:4297-4303. https://doi.org/10.1021/ jf073471e.

Christie, W. W., and X. Han. 2012. Lipid Analysis: Isolation, Separation, Identification and Lipidomic Analysis. 4th ed. An Oil Press Title. WP, Woodhead Publishing Limited.

Cossignani, L., F. Blasi, A. Bosi, G. D'Arco, S. Maurelli, M. S. Simonetti, and P. Damiani. 2011. Detection of cow milk in donkey milk by chemometric procedures on triacylglycerol stereospecific analysis results. J. Dairy Res. 78:335-342. https://doi.org/10 .1017/S0022029911000495

Cossignani, L., F. Blasi, M. S. Simonetti, and D. Montesano. 2017. Fatty acids and phytosterols to discriminate geographic origin of Lycium barbarum berry. Food Anal. Methods 11:1180-1188. https: //doi.org/10.1007/s12161-017-1098-5.

Cossignani, L., L. Giua, G. Lombardi, M. S. Simonetti, P. Damiani, and F. Blasi. 2013. Analysis of CLA isomer distribution in nutritional supplements by single column silver-ion HPLC. J. Am. Oil Chem. Soc. 90:327-335. https://doi.org/10.1007/s11746-012-2176 $-\mathrm{x}$.

Cossignani, L., L. Giua, E. Urbani, M. S. Simonetti, and F. Blasi. 2014. Fatty acid composition and CLA content in goat milk and cheese samples from Umbrian market. Eur. Food Res. Technol. 239:905-911. https://doi.org/10.1007/s00217-014-2287-8.

Cubero-Leon, E., R. Peñalver, and A. Maquet. 2014. Review on metabolomics for food authentication. Food Res. Int. 60:95-107. https://doi.org/10.1016/j.foodres.2013.11.041.

Delmonte, P., A. Kataoka, B. A. Corl, D. E. Bauman, and M. P. Yurawecz. 2005. Relative retention order of all isomers of cis/trans conjugated linoleic acid FAME from the 6,8- to 13,15-positions us- ing silver ion HPLC with two elution systems. Lipids 40:509-514. https://doi.org/10.1007/s11745-005-1411-3.

Di Stefano, V., G. Avellone, D. Bongiorno, V. Cunsolo, V. Muccilli, S. Sforza, A. Dossena, L. Drahosd, and K. Vékey. 2012. Applications of liquid chromatography-mass spectrometry for food analysis. J. Chromatogr. A. 1259:74-85. https://doi.org/10.1016/j.chroma .2012.04.023.

Dugo, P., T. Kumm, B. Chiofalo, A. Cotroneo, and L. Mondello. 2006. Separation of triacylglycerols in a complex lipidic matrix by using comprehensive two-dimensional liquid chromatography coupled with atmospheric pressure chemical ionization mass spectrometric detection. J. Sep. Sci. 29:1146-1154. https://doi.org/10.1002/jssc 200500476 .

EU-JRC (European Union-Joint Research Centre). 2018. https:// ec.europa.eu/jrc/en/food-fraud-and-quality/monthly-summary -articles.

Folch, J., M. Lees, and G. H. S. Stanley. 1957. A simple method for the isolation and purification of total lipids from animal tissues. J. Biol. Chem. 226:497-509.

Fontecha, J., H. Goudjil, J. J. Ríos, M. J. Fraga, and M. Juárez. 2005. Identity of the major triacylglycerols in ovine milk fat. Int. Dairy J. 15:1217-1224. https://doi.org/10.1016/j.idairyj.2004.11.013.

Fontecha, J., J. J. Ríos, L. Lozada, M. J. Fraga, and M. Juárez. 2000. Composition of goat's milk fat triglycerides analysed by silver ion adsorption-TLC and GC-MS. Int. Dairy J. 10:119-128.

Garwolińska, D., W. Hewelt-Belka, J. Namieśnik, and A. Kot-Wasik. 2017. Rapid characterization of the human breast milk lipidome using a solid-phase microextraction and liquid chromatographymass spectrometry-based approach. J. Proteome Res. 16:32003208. https://doi.org/10.1021/acs.jproteome.7b00195.

Gastaldi, D., C. Medana, V. Giancotti, R. Aigotti, F. Dal Bello, and C. Baiocchi. 2011. HPLC-APCI analysis of triacylglycerols in milk fat from different sources. Eur. J. Lipid Sci. Technol. 113:197-207. https://doi.org/10.1002/ejlt.201000068.

Gotoh, N., Y. Matsumoto, T. Nagai, H. Mizobe, K. Yoshinaga, K. Kojima, I. Kuroda, Y. Kitamura, T. Shimizu, H. Ishida, and S. Wada. 2012. Actual ratio of triacylglycerol positional isomers in milk and cheese. J. Oleo Sci. 61:173-180. https://doi.org/10.5650/ jos.61.173.

Gutiérrez, R., S. Vega, G. Diaz, J. Sanchez, M. Coronado, A. Ramirez, J. Pérez, M. González, and B. Schettino. 2009. Detection of nonmilk fat in milk fat by gas chromatography. J. Dairy Sci. 92:18461855. https://doi.org/10.3168/jds.2008-1624.

Hrbek, V., L. Vaclavik, O. Elich, and J. Hajslova. 2014. Authentication of milk and milk-based foods by direct analysis in real time ionization-high resolution mass spectrometry (DARTeHRMS) technique: A critical assessment. Food Control 36:138-145. https:/ /doi.org/10.1016/j.foodcont.2013.08.003.

ISO (International Standardization Organization). 2010a. ISO 1211:2010 (IDF 1:2010). Milk-Determination of fat content-Gravimetric method (Reference method). ISO, Geneva, Switzerland.

ISO (International Standardization Organization). 2010b. ISO 17678:2010 (IDF 202: 2010). Milk and milk products-Determination of milk fat purity by gas chromatographic analysis of triglycerides. ISO, Geneva, Switzerland.

Jensen, R. G. 2002. The composition of bovine milk lipids: January 1995 to December 2000. J. Dairy Sci. 85:295-350. https://doi.org/ 10.3168/jds.S0022-0302(02)74079-4.

Kalo, P., A. Kemppinen, V. Ollilainen, and A. Kuksis. 2004. Regiospecific determination of short-chain triacylglycerols in butter by normal-phase HPLC with on-line electrospray-tandem mass spectrometry. Lipids 39:915-928. https://doi.org/10.1007/s11745-004 $-1314-3$.

Li, Q., Y. Zhao, D. Zhu, X. Pang, Y. Liu, R. Frew, and G. Chen. 2017. Lipidomics profiling of goat milk, soymilk and bovine milk by UPLC-Q-Exactive Orbitrap mass spectrometry. Food Chem. 224:302-309. https://doi.org/10.1016/j.foodchem.2016.12.083.

Li, Y., F. G. Naghdi, S. Garg, T. C. Adarme-Vega, K. J. Thurecht, W. A. Ghafor, S. Tannock, and P. M. Schenk. 2014. A comparative study: The impact of different lipid extraction methods on current 
microalgal lipid research. Microb. Cell Fact. 13:14-23. https://doi .org/10.1186/1475-2859-13-14.

Lipp, M. 1995. Review of methods for the analysis of triglycerides in milk fat: Application for studies of milk quality and adulteration. Food Chem. 54:213-221.

Liu, Z., S. Rochfort, and B. Cocks. 2016. Optimization of a single phase method for lipid extraction from milk. J Chromatogr. A 1458:145-149. https://doi.org/10.1016/j.chroma.2016.06.055.

Liu, Z., S. Rochfort, and B. Cocks. 2018. Milk lipidomics: What we know and what we don't. Prog. Lipid Res. 71:70-85. https://doi .org/10.1016/j.plipres.2018.06.002.

Luque de Castro, M. D., and F. Priego-Capote. 2010. Soxhlet extraction: Past and present panacea. J. Chromatogr. A. 1217:23832389. https://doi.org/10.1016/j.chroma.2009.11.027.

Månsson, H. L. 2008. Fatty acids in bovine milk fat. Food Nutr. Res. 52:1-4. https://doi.org/10.3402/fnr.v52i0.1821.

Maurelli, S., F. Blasi, L. Cossignani, A. Bosi, M. S. Simonetti, and P. Damiani. 2009a. Production and structural analysis of triacylglycerols containing capric acid and conjugated linoleic acid isomers obtained by enzymatic acidolysis. J. Sci. Food Agric. 89:25952600. https://doi.org/10.1002/jsfa.3760.

Maurelli, S., F. Blasi, L. Cossignani, A. Bosi, M. S. Simonetti, and P. Damiani. 2009b. Enzymatic synthesis of structured triacylglycerols containing CLA isomers starting from sn-1,3-diacylglycerols. J. Am. Oil Chem. Soc. 86:127-133. https://doi.org/10.1007/s11746 -008-1334-7.

Molkentin, J., and D. Precht. 2000. Equivalence of packed and capillary GC columns with respect to suitability for foreign fat detection in butter using the triglyceride formula method. Chromatographia 52:791-797. https://doi.org/10.1007/BF02491006.

Montesano, D., F. Blasi, M. S. Simonetti, A. Santini, and L. Cossignani. 2018. Chemical and nutritional characterization of seed oil from Cucurbita maxima L. (var. Berrettina) pumpkin. Foods 7:30. https://doi.org/10.3390/foods7030030.

Mottram, H. R., and R. P. Evershed. 2001. Elucidation of the composition of bovine milk fat triacylglycerols using high-performance liquid chromatography atmospheric pressure chemical ionization mass spectrometry. J. Chromatogr. A. 926:239-253.

Nikolova-Damyanova, B. 2009. Retention of lipids in silver ion highperformance liquid chromatography: Facts and assumptions. J. Chromatogr. A. 1216:1815-1824. https://doi.org/10.1016/j .chroma.2008.10.097.

Pérez-Palacios, T., J. Ruiz, D. Martín, E. Muriel, and T. Antequera 2008. Comparison of different methods for total lipid quantification in meat and meat products. Food Chem. 110:1025-1029. https://doi.org/10.1016/j.foodchem.2008.03.026.

Picariello, G., R. Sacchi, and F. Addeo. 2007. One-step characterization of triacylglycerols from animal fat by MALDI-TOF MS. Eur. J. Lipid Sci. Technol. 109:511-524. https://doi.org/10.1002/ejlt 200600255.

Řezanka, T., K. Pádrová, and K. Sigler. 2017. Regioisomeric and enantiomeric analysis of triacylglycerols. Anal. Biochem. 524:3-12. https://doi.org/10.1016/j.ab.2016.05.028.

Sardenne, F., N. Bodin, L. Metral, A. Crottier, F. Le Grand, A. Bideau, B. Brisset, J. Bourjea, C. Saraux, S. Bonhommeau, V.
Kerzérho, S. Bernard, and T. Rouyer. 2019. Effects of extraction method and storage of dry tissue on marine lipids and fatty acids. Anal. Chim. Acta 1051:82-93. https://doi.org/10.1016/j.aca.2018 .11 .012 .

Smiddy, M. A., T. Huppertz, and S. M. van Ruth. 2012. Triacylglycerol and melting profiles of milk fat from several species. Int. Dairy J. 24:64-69. https://doi.org/10.1016/j.idairyj.2011.07.001.

Taylor, M. V., and A. MacGibbon. 2011. Milk Lipids-Triacylglycerols. Reference Module in Food Science Encyclopedia of Dairy Sciences 665-669. Academic Press, 2nd ed. https://doi.org/10.1016/B978-0 -12-374407-4.00334-4.

Ten-Doménech, I., E. Beltrán-Iturat, J. Manuel Herrero-Martínez, J. V. Sancho-Llopis, and E. F. Simó-Alfonso. 2015. Triacylglycerol analysis in human milk and other mammalian species: small-scale sample preparation, characterization, and statistical classification using HPLC-ELSD profiles. J. Agric. Food Chem. 63:5761-5770. https://doi.org/10.1021/acs.jafc.5b01158.

Tolentino, R. G., S. Vega y León, M. N. Pérez, M. C. Herrera, A. R. Ayala, J. J. P. González, B. S. Bermúdez, R. O. Salinas, M. V. Francisca, and J. G. Rivera Martínez. 2015. Composition of triacylglycerols in fats of cow and goat milk produced in four zones of Mexico. Food Nutr. Sci. 6:555-561. https://doi.org/10.4236/fns .2015.66058

Turon, F., P. Bachain, Y. Caro, M. Pina, and J. Graille. 2002. A direct method for regiospecific analysis of TAG using $\alpha$-MAG. Lipids $37: 817-821$.

Tzompa-Sosa, D. A., P. P. Meurs, and H. J. F. van Valenberg. 2018. Triacylglycerol profile of summer and winter bovine milk fat and the feasibility of triacylglycerol fragmentation. Eur. J. Lipid Sci. Technol. 120:1700291. https://doi.org/10.1002/ejlt.201700291.

Tzompa-Sosa, D. A., G. A. van Aken, A. C. van Hooijdonk, and H. J van Valenberg. 2014. Influence of C16:0 and long-chain saturated fatty acids on normal variation of bovine milk fat triacylglycerol structure. J. Dairy Sci. 97:4542-4551. https://doi.org/10.3168/jds .2014-7937.

Tzompa-Sosa, D. A., H. J. van Valenberg, G. A. van Aken, and H. Bovenhuis. 2016. Milk fat triacylglycerols and their relations with milk fatty acid composition, DGAT1 K232A polymorphism, and milk production traits. J. Dairy Sci. 99:3624-3631. https://doi .org/10.3168/jds.2015-10592.

Valeille, K., and J. C. Martin. 2004. Complete stereospecific determination of conjugated linoleic acids in triacylglycerol of milkfat. Reprod. Nutr. Dev. 44:459-464. https://doi.org/10.1051/rnd: 2004048

Villaseñor, A., I. Garcia-Perez, A. Garcia, J. M. Posma, M. FernandezLopez, A. J. Nicholas, N. Modi, E. Holmes, and C. Barbas. 2014 Breast milk metabolome characterization in a single-phase extraction, multiplatform analytical approach. Anal. Chem. 86:82458252. https://doi.org/10.1021/ac501853d.

Zhou, Q., B. Gao, X. Zhang, Y. Xu, H. Shi, and L. Yu. 2014. Chemical profiling of triacylglycerols and diacylglycerols in cow milk fat by ultra-performance convergence chromatography combined with a quadrupole time-of-flight mass spectrometry. Food Chem. 143:199-204. https://doi.org/10.1016/j.foodchem.2013.07.114. 